\title{
BREVES REFLEXÕES SOBRE OS EFEITOS DA PERDA DE MEMÓRIA DE UMA AMIGA EM DESARTICULACIONES, DE SYLVIA MOLLOY
}

\section{RENATA CRISTINA PEREIRA RAULINO}

RESUMO: Em uma atualidade em que o exercício da memória é tão intenso, há produções literárias que criam e pensam a perda da memória, como a causada pelo Alzheimer. Em vista disso, proponho algumas reflexões sobre os efeitos do esquecimento em Desarticulaciones (2010), de Sylvia Molloy. Nesse texto, a narradora relata as visitas à ML., amiga que está com Alzheimer. A partir desses encontros e dos fragmentos de esquecimento que presencia, a voz narrativa constrói um relato sobre a desarticulação da memória da amiga que vai apagando as lembranças que compartilham. Em vista disso, concluo que a narradora expressa especialmente a ausência, se concentra no que falta e evidencia o esquecimento para exibir os vazios da memória em decomposição da amiga enferma.

PALAVRAS-Chave: memória, esquecimento, Alzheimer; Desarticulaciones; Sylvia Molloy.

No livro En busca del futuro perdido: Cultura y memoria en tiempos de globalización, Andreas Huyssen (2002) argumenta que se no início do século XX a cultura ocidental colocava sua atenção nas transformações e tecnologias que a humanidade empreendia para construir uma visão futurista das sociedades, na última década do século passado e neste início do XXI, o desejo de imaginar um futuro cede espaço para a revisão do passado em uma grande variedade de manifestações artístico-culturais. Portanto, em um momento em que o exercício da memória é tão intenso, a escritura parece ser uma espécie de remédio que nos ajuda a lembrar. 
Por sua vez, concordo com Harald Weinrich (2001), em Lete: arte e crítica do esquecimento, quando argumenta que a escrita é também aliada do esquecimento se pensamos somente na nossa memória natural, pois a revolução escritural das sociedades ocidentais deixou preguiçosa nossa capacidade de lembrar. Por isso, muitas vezes, escrever se relaciona a uma condição da memória que expõe suas limitações: o que alguém escreve no papel frequentemente se retira da memória natural e, por conseguinte, se esquece.

Em vista disso, apresentarei uma análise breve dos efeitos da escritura do esquecimento em Desarticulaciones, de Sylvia Molloy. Neste texto, a narradoraescritora escreve as visitas que faz a ML., amiga que está com Alzheimer, doença neurodegenerativa que pode levar à perda da memória, da linguagem, da noção de tempo, da direção, da autopercepção e do autocontrole. A partir desses encontros e dos fragmentos de esquecimento que presencia, a voz narrativa constrói uma espécie de diário sobre a desarticulação da memória da amiga que vai apagando as lembranças que compartilham. A narradora escreve sobre uma situação limite que a leva a questionar-se sobre a memória e sua perda, o lugar de origem e os próprios limites e possibilidades da escritura em expressar tais problemáticas.

Dessa maneira, a escritora constrói ML. como um animal obliviscens, um ser que esquece. A preocupação em relatar a perda da memória alheia demonstra uma consciência de que a luta contra essa doença parece ser inevitavelmente perdida: ao invés de mostrar somente a presença da memória em ruínas, a narradora enfatiza o que falta e evidencia o esquecimento, não somente para selecionar lembranças, mas também, e principalmente, para exibir os vazios da memória.

Portanto, a voz narrativa se propõe mais a questionar e a refletir sobre os movimentos da memória, que oscila entre o lembrar e o esquecer, do que a relatar as lembranças que a amiga está perdendo. Nesse sentido, em uma entrevista para Mauro Libertella para o jornal Clarín, Sylvia nega que o relato seja uma desarticulação que progride em linha reta. Cito um trecho da entrevista:

[Não] [...] quise registrar el progreso de esa desarticulación, no se trata del itinerario de un derrumbe sino de un ir y venir (hoy se acuerda de cómo leer, ayer no se acordaba, hoy sabe su nombre, mañana no lo sabrá). (LIBERTELLA; MOLLOY, 2010) 
No entanto, a ênfase está nos efeitos do esquecimento, especialmente nos que afetam a relação de amizade entre a narradora e sua amiga desmemoriada. Lemos fissuras de um passado e uma forte presença do que está se ausentando. Cito um trecho de Desarticulaciones: "No escribo para remendar huecos [...] sino para atestiguar incoherencias, hiatos, silencios" (MOLLOY, 2010, p. 38). Por isso, Desarticulaciones é fragmentário e repetitivo com uma temporalidade muito mais próxima do presente que de um passado perdido, narração muito semelhante ao tom de um diário que se desvia da reconstrução de um passado para concentrar-se na sua inevitável e presente perda. Na mesma entrevista que mencionei, Sylvia justifica a sua escolha pela forma fragmentária, a que ela chama de "forma breve":

la forma breve me permite recalcar la pobreza de esos encuentros, o mejor dicho su carácter elemental. Son contactos pequeños que apuntan a un mundo más grande que se ha perdido y del que sólo subsisten ecos, susurros y alguna que otra iluminación que de pronto surge de la desmemoria. (LIBERTELLA; MOLLOY, 2010)

Ao relatar a história da doença da amiga como parte fundamental da sua própria narrativa de vida, a voz narrativa também luta e conta com o esquecimento para escrever. Ela descreve suas limitações e dificuldades, que parecem estar relacionadas ao contato com uma amiga com distúrbios da memória e da linguagem. Assim, não parece somente usar a memória contra o esquecimento, mas também explicita seus mecanismos na escrita, tanto em sua forma quanto em seu conteúdo. Portanto, a narradora extrema a seguinte reflexão de Sergio Chejfec (2015) em "Lengua simple, nombre": "escribir no es recordar; sino al contrario, delimitar lo que es imposible de recuperar".

Por exemplo, em um fragmento ou uma entrada dessa espécie de diário de esquecimentos intitulado "Expectativa", a narradora se questiona sobre o que aconteceria se as cuidadoras de ML. não a preparassem para a sua visita:

Ayer fue por alguna alguna razón una visita particularmente patética, es decir, yo me quedé melancólica. Son los únicos sentimientos de los que puedo dar cuenta, los míos; los de ella son casi imposibles de leer, más allá de la sonrisa o de una 
exclamación de dolor. Yo me quedé melancólica; ella no creo que se ha quedado nada. Me estaba esperando cuando llegué, es decir, la habían preparado para que me estuviera esperando, diciéndole cada tanto que yo estaba por llegar para crear, siquiera por un momento, una actitud de espera. Me pregunto qué ocurriría si no le anunciaran mi visita, si de verme aparecer de pronto me reconocería; prefiero no averiguar. (MOLLOY, 2010, p. 29)

No trecho transcrito, a narradora enfatiza o que é impossível de recuperar ou de obter uma resposta: como em outros fragmentos do texto, declara a sua incapacidade de ler/entender os sentimentos ou expressões da amiga, mas levantando a hipótese de que ela não sente mais nada. Em seguida, se pergunta como ML. se comportaria se não a preparassem para a sua chegada, mas, logo em seguida, declara não querer uma resposta.

Por sua vez, lemos no fragmento "De la propiedad en el lenguaje":

Ayer descubrí que me había vuelto aún menos yo para ella. La llamé y a pesar de que L. le pasó el teléfono diciéndole quién llamaba me habló de tú - de tú y no de vos - durante la conversación. Fue una conversación cordial y eminentemente correcta en un español que jamás habíamos hablado. Sentí que había perdido algo más de lo que quedaba de mí. (MOLLOY, 2010, p. 37, grifo meu)

O "voseo" é a forma de tratamento informal na Argentina, país de origem das duas amigas que, no presente da enunciação de Desarticulaciones, vivem em Nova York há muitos anos. O "tuteo" parece indicar que ML. desconhece e, ao mesmo tempo, "estrangeiriza" a narradora, expulsando-a de um espaço-tempo $\operatorname{argentino}^{1}$ que parece sobreviver somente na memória compartilhada das amigas. Sendo assim, pedaços do passado da voz narrativa estão nas mãos da amiga. Cito: "No quedan testigos de una parte de mi vida, la que su memoria ha llevado consigo" (MOLLOY, 2010, p. 22). Parte do seu próprio eu está se perdendo na medida em que a memória da amiga se desarticula.

Entretanto, a escritora resiste e não abre mão dessas ruínas de lembranças em um texto dominado pelo esquecimento. Está atenta aos restos de linguagem

1 Sobre a relação entre memória e sua perda, língua e deslocamentos, cf. artigo de Adriana Kanzepolsky (2014), “Su 'acumulación primitiva': Desarticulaciones, de Sylvia Molloy”. 
que ainda sobrevivem na amiga porque é por meio dessa língua arruinada, a qual compartilham, que se mantêm no presente restos de um tempo e de um lugar que viveram juntas. No fragmento "Rememoración”, escreve:

\footnotetext{
No puedo acostumbrarme a no decir "te acordás" porque intento mantener, en esos pedacitos de pasado compartido, los lazos cómplices que me unen a ella. Y porque para mantener una conversación - para mantener una relación - es necesario hacer memoria juntas o jugar a hacerla aun cuando - ella, es decir, su memoria ya ha dejado sola a la mía. (MOLLOY, 2010, p. 33)
}

A que esquece não é esquecida. A escritora não escreve contra o esquecimento (batalha perdida), mas sim textualiza uma relação que "todavía está". Por conseguinte, a voz narrativa atribui a si uma memória desmedida que invade sem controle o seu presente, perguntando-se se isso seria uma reação à perda da memória de ML. no fragmento "Pasajes de memoria". Em contrapartida, em "Fractura”, que vem logo depois desse fragmento, a narradora relata a fratura de uma perna e sua recuperação no hospital. Em tal fragmento, a história de ML. e o acidente que sofre a voz narrativa confundem-se: a fratura da perna traz consigo uma desmemória parecida com a de sua amiga porque a escritora também esqueceu o que aconteceu enquanto esteve hospitalizada. Entretanto, posteriormente a esse acidente, relata que a sua memória entrou em um estado febril, em um "abarrotamiento digno de Funes"2 (MOLLOY, 2010, p. 62) como um modo de não ceder ao pânico do próprio esquecimento. Se considerarmos uma doença uma anormalidade corporal, a memória da narradora está enferma por sua desmedida. Em contrapartida, a memória de ML. estaria doente pela sua incontrolável e irreversível perda. Portanto, concordamos com Mauro Libertella (2010) quando afirma que a narradora que visita a sua amiga com Alzheimer se converte subitamente, sem querer querendo, na mente e na mão que perpetuam a/permanecem na palavra escrita para escrever o eclipse da memória de ML. Concluo com uma interpretação provisória: a escritora-narradora constrói a amiga doente e a si mesma como seres interdependentes que se transformam e se constroem nessa relação de amizade. Seria por isso que o esquecimento causado pelo Alzheimer afeta as duas amigas, pois a memória em decomposição de uma delas impacta e

2 Referência ao personagem principal do conto de Jorge Luis Borges, "Funes, el memorioso". 
ameaça o relacionamento das duas e, por conseguinte, as suas próprias constituições subjetivas.

A narradora não escreve uma relação de dependência de uma sobre a outra, mas de codependência que qualquer relacionamento pressupõe. Talvez o adoecimento de uma das pessoas envolvidas tenha tornado esse fator mais explícito e intenso, o que suscitou a própria existência de Desarticulaciones. A escritora descreve alguns efeitos de uma doença em outro sujeito e os impactos da transformação dessa relação com o advento do Alzheimer na vida afetiva entre ela e sua amiga: a transformação de ML. em uma pessoa diferente da que a narradora conhecia leva a uma relação incontornável com alguém subjetivamente instável para que o vínculo continue, ainda que sob ameaça da desarticulação e com uma forte dependência da sua memória exacerbada, mas que também não é impassível às quedas no esquecimento ou ao descontrole sobre o que lembra e o que esquece.

\section{REFERÊNCIAS}

BORGES, Jorge Luis. Funes, el memorioso. In: Borges esencial. Barcelona: Penguim Random House, 2017.

CHEJFEC, Sergio. Lengua simple, nombre. Asymptote, 2015. Disponível em: <https://www.asymptotejournal.com/nonfiction/sergio-chejfec-simple-language-name/spanish/>. Acesso em: 03 ago. 2018.

HUYSSEN, Andreas. En busca de un futuro perdido: cultura y memoria en tiempos de globalización. Ciudad de México: Fondo de Cultura Económica, 2002.

KANZEPOLSKY, Adriana. Su "acumulación primitiva”: “Desarticulaciones”, de Sylvia Molloy. Hispamérica, v. 43, n. 129, dez. 2014. Disponível em: <https://www.jstor.org/stable/43684395?-seq=1\#page_scan_tab_cotents>. Acesso em: 04 ago. 2018.

MOLLOY, Sylvia. Desarticulaciones. Buenos Aires: Eterna Cadencia, 2010.

MOLLOY, Sylvia; LIBERTELLA, Mauro. La escritura del olvido. Clarín - Revista Ñ, 19 out. 2010. Disponível em: <https://www.clarin.com/rn/literatura/no-ficcion/escritura-olvido_0_ry-W_qipwml.-html>. Acesso em: 02 fev. 2018. 